\title{
A METHOD FOR COMPUTING SHALLOW ICE-CORE DEPTHS
}

\author{
By IAN M. Whillans and JoHn F. BOLzaN
}

(Byrd Polar Research Center and Department of Geology and Mineralogy,

The Ohio State University, Columbus, Ohio 43210, U.S.A.)

ABSTRACT. SIPRE-style hand augers usually recover core sections whose bottom is somewhat shallower than the drill depth. A procedure for calculating the range of possible core depths is presented.

\section{INTRODUCTION}

A design for shallow hand augers which originated at the Snow, Ice and Permafrost Research Establishment (SIPRE) is commonly used to recover firn and ice cores (Koci, 1984; Rand and Mellor, 1985). Over several field seasons we have used these augers to drill shallow cores for the purpose of determining the net accumulation rate at various sites in Antarctica and Greenland. To compute the net accumulation rate, the depths of dated horizons in gross beta activity are needed as well as the depth-integrated density or "load" above the horizons. Lost core must also be accounted for and the depth of all samples estimated as accurately as possible.

While the SIPRE auger is simple and reliable, there can be difficulty in determining the depth from which samples originate. The problem arises in part because of the system of core "catching" and how the core breaks as the drill is pulled to the surface. The lower end of the SIPRE barrel is tapered so that the inside diameter is smaller near the cutting head. As drilling proceeds, the free space between the barrel and the core fills with drilling chips. When a coring run is finished, the operator pulls up on the auger and the barrel slips upward over the core, and chips are dragged and lodged tightly in the taper. As the auger continues to rise, the chips are more tightly wedged until the friction becomes adequate to grip, hold, and break the core. The amount of slippage before the core is lifted is variable but it is commonly $0.1-0.2 \mathrm{~m}$. The core can break at any point between the bottom of the hole and the position where the auger grips the core. Thus, the base of the core section generally comes from a depth that is not simply determinable.

A second difficulty in estimating core depths arises because there are usually lost sections of core. This loss is partly due to shearing and destruction of core during drilling and partly because core protruding from the lower end of the barrel occasionally falls to the bottom of the hole where it is ground up on the next run. In shallow firn, which can be very friable, losses of hundreds of millimeters are common, and in deeper firn significant losses can occur at depth-hoar strata. In either case, there is usually no clear indication of the level at which the loss occurred.

Core depth cannot easily be determined through the use of a separate probe. This is because the drilling process results in a layer of chips and ground-up core being left at the bottom of the hole at the end of each run. This layer can of ten be greater than $0.2 \mathrm{~m}$ thick (depending on the amount of ground-up core and chips that falls back into the hole as the auger is retrieved), and is usually strong enough to support the weight of the auger. The presence of this layer of chips and core pieces precludes the possibility of lowering a device down the bore hole to measure the depth directly.

\section{METHODS}

In the field, the drill barrel is lowered down the hole by means of a series of rigid extension rods. The apparatus is then rotated to drill through debris left behind by the prior run and into fresh firn or ice. (Care is taken to ensure that the total penetration of debris and firn does not exceed about half the length of the drill barrel, otherwise the barrel's capacity for core and chips will be exceeded and the drill likely jammed.) The entire apparatus is then recovered. The workers record the run number, the total drill length (barrel and extensions), the exposed length of extensions above the hole top at the end of drilling, and the length of recovered core. The cycle is then repeated.

An example is shown in Table I. These data are then used to calculate drill depth, which is drill length minus the exposed length, plus an adjustment if drilling is from the base of a pit. Distance drilled is then obtained by comparison with the drill depth of the prior run. The apparent core loss is the distance drilled minus the length of recovered core. The actual core loss is not readily calculated; it is the sum of true core loss (ground-up core and the collapse of friable strata) and the amount of core left behind as the auger is raised to the surface. The apparent core loss, as calculated here, is usually positive, but it can be negative (core gain) if core augered and left behind by a prior run is recovered. The summed apparent core loss (SACL) is the running sum of apparent core loss.

The next step is to identify certain "special runs", designated by asterisks $\left(^{*}\right)$ in Table I. This is done by making the deepest run a "special run" (this issue is discussed later). One then scans up the SACL column, identifying each SACL which is less then the current minimum.

The major assumption here is that the core does sometimes break at the hole bottom. These "special runs" are the only runs for which core could have broken at the hole bottom and then been recovered. For these runs, the SACL is the true amount of core destroyed down to that point. Other runs have SACLs that are larger than the true core loss. Thus, special runs have minima in SACL as compared with neighboring runs.

The reason that the special runs are obtained from successively decreasing values rather than from local minima in SACL is because true core loss must increase with depth. Thus, if two local minima are to be special runs, the shallower one must have a smaller SACL. In Table I, run 14 is an example of a local minimum that is not a special run. Runs 14 and 16 both have local minima in SACL but, if both are taken to be special runs, then true core loss decreases (from $0.52 \mathrm{~m}$ to $0.50 \mathrm{~m}$ ) for these runs. This is clearly impossible and is equivalent to recovering more core between the two local minima than the actual distance drilled. Thus, only values for which SACL progressively decreases upward can be special runs.

Once the special runs have been identified, a generally small ambiguity remains as to how core loss should be distributed. The difference in SACL between special runs is the true core loss between those runs. However, it is not clear how this core loss should be distributed between the special runs. In the extreme cases, it can be placed at 
TABLE I. A TYPICAL EXAMPLE (SUMMIT CAMP, CENTRAL GREENLAND, 1987). LENGTHS ARE IN METERS AND CORING IS DONE FROM THE BOTTOM OF A $2 \mathrm{~m}$ PIT. BASIC DATA ARE IDENTIFIED WITH DAGGERS $(+)$. SPECIAL RUNS ARE INDICATED WITH ASTERISKS $(*)$. THE EXTREME CASES FOR THE DISTRIBUTION OF CORE DISCUSSED IN THE TEXT ARE HERE LABELLED "ABOVE" (CORE LOSS INSERTED AT THE TOP OF THE INTERVAL BETWEEN TWO ADJACENT SPECIAL RUNS), AND "BELOW" (CORE LOSS INSERTED AT THE BOTTOM OF THE SAME INTERVAL). CALCULATED DEPTHS REFER TO THE BASE OF THE CORE SECTION. THE RANGE IS ONE-HALF THE DIFFERENCE IN THE DEPTHS CALCULATED BY THE TWO EXTREME CASES, AND IS A MEASURE OF THE PRECISION IN CORE DEPTHS

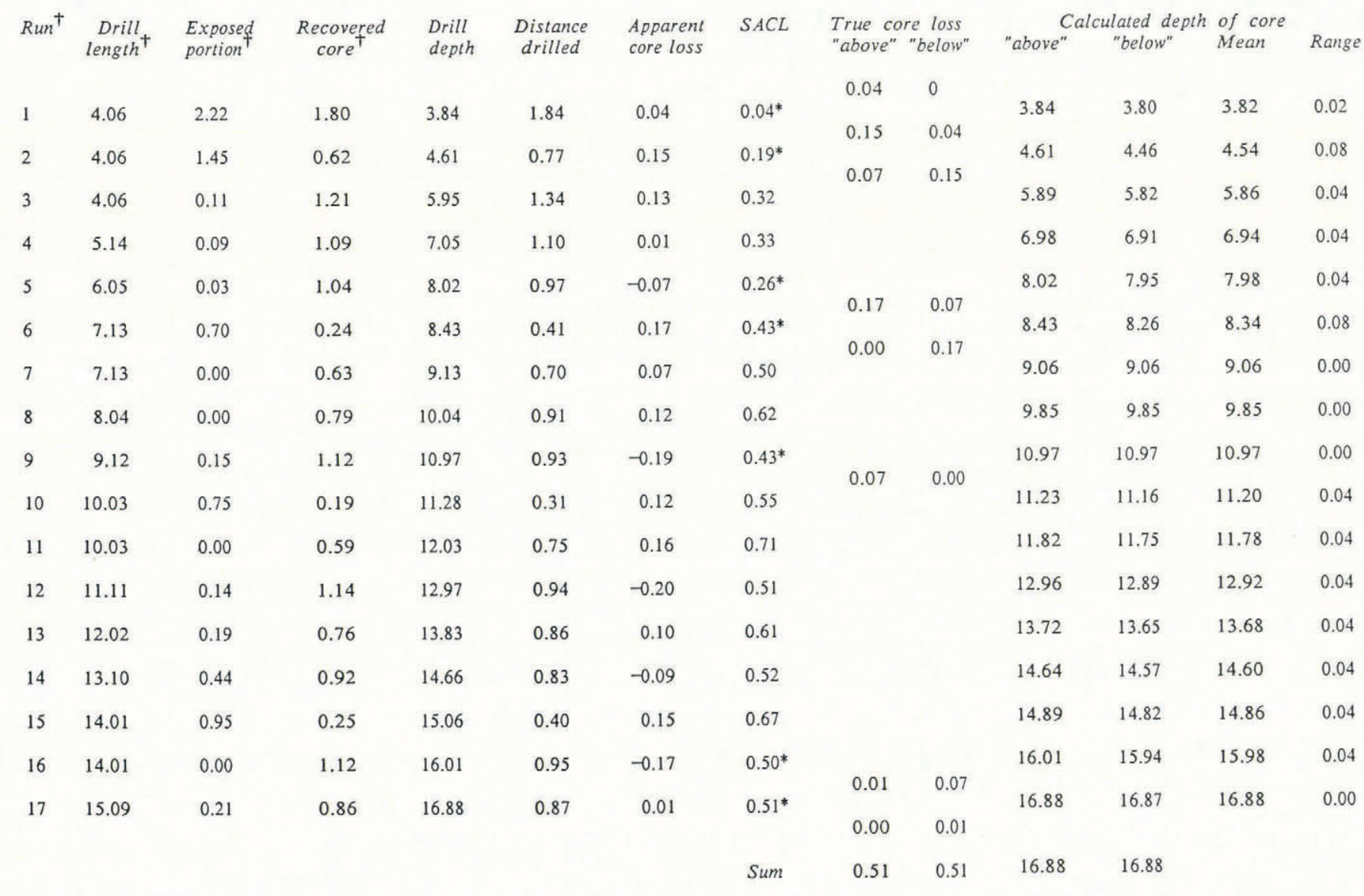

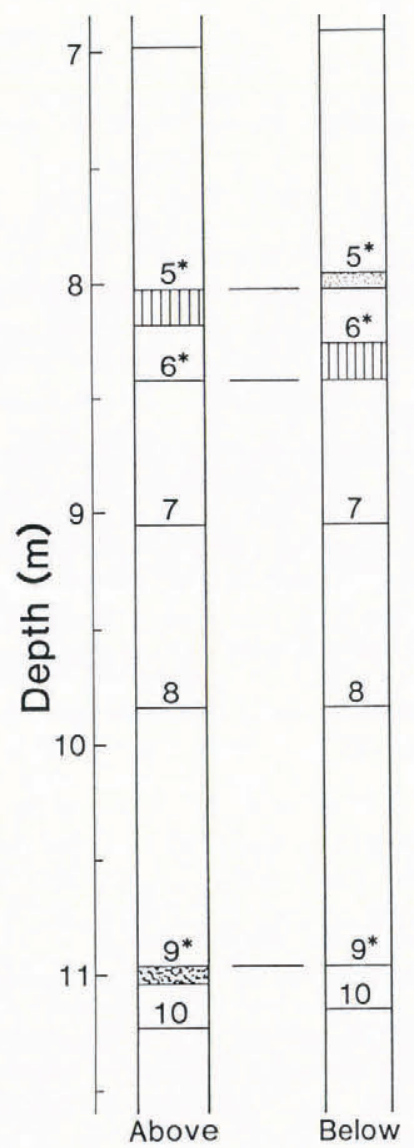

either end of the interval between the special runs. In the first extreme (labelled "above" in Table I and Figure 1), the core loss is placed on top of the interval between special runs. This results in assigned core depths that are as deep as possible. In the other extreme (labelled "below"), loss is placed at the bottom of the special-run interval. This would be appropriate if the core break occurred at the hole bottom, but core slipped out of the drill barrel as it was raised to the surface and this core was subsequently destroyed. Neither extreme is very likely, and other sources of core loss, such as grinding between core segments in the barrel and the collapse of very low-density depth hoar, result in core depths that lie between these two extremes. The distribution of core loss according to the two extremes encompasses all reasonable possibilities, and the extremes lead to a conservative measure of precision.

The core depths are then calculated by summing recovered core lengths and the true core-loss estimates. The example in Table $\mathrm{I}$ is fairly typical. The core barrel was $2 \mathrm{~m}$ long.

Fig. 1. Representation of core segments on a depth scale. It shows two extreme versions for the assignment of core loss for a part of the core in Table I. Special runs for which the core break is taken to have occurred at the bottom of the hole are indicated with an asterisk (*). In the "above" case, core loss is placed high in the interval between special runs. In the "below" case, the calculated loss is placed low in the interval. Special runs 6 and 9 happen to have the same summed apparent core loss (SACL); thus there is zero core loss to be distributed between them. 


\section{DISCUSSION}

The method is a systematic procedure for calculating a very probable distribution of core loss, as well as realistic error limits to the assigned core depths. As is reasonable, the core loss is usually distributed in the first few runs where the firn is most friable.

A detailed algebraic discussion of the method is not included here. However, it can be proved that the special runs, as determined by the method discussed here, are the only possible runs for which the core breaks at the hole bottom. Without important additional information, it cannot, however, be proved that special runs must break at the hole bottom.

Additional information to help in assigning core depths may be available in the closer study of recovered core. Sometimes there are small steps in the sides of core sections. These may indicate the position of the start of an auger run which was a little eccentric from the prior run. Perhaps these steps can be used to limit more narrowly core depths.

The deepest run is always calculated to be a special run, but there is no physical reason why the core should break at the hole bottom for that run. The effect of making the deepest run a special run is to broaden the depth imprecision. If drilling had proceeded deeper, that run would perhaps not be a special run, but the calculated depths would still be in the range given by this method.

\section{ACKNOWLEDGEMENTS}

Thanks are due to $R$. Frederking and the referees for helpful suggestions. This work was supported by U.S. National Science Foundation grants DPP-8117235 and DPP8520855. This is Byrd Polar Research Center contribution number 626 .

\section{REFERENCES}

Koci, B.R. 1984. A lightweight hand coring auger. CRREL Spec. Rep. 84-34, 55-59.

Rand, J. and M. Mellor. 1985. Ice-coring augers for shallow depth sampling. CRREL Rep. 85-21.

MS. received 20 November 1986 and in revised form 6 May 1988 